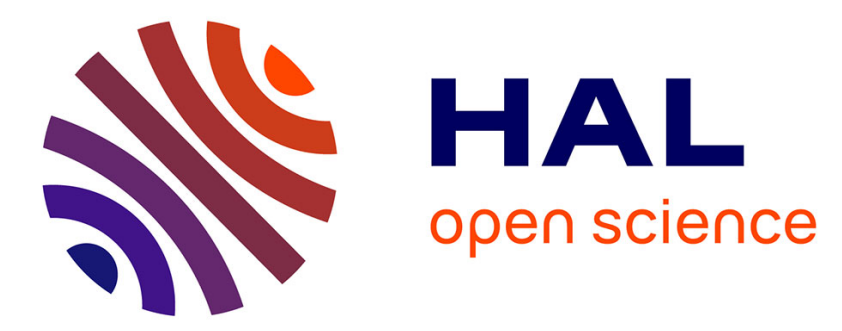

\title{
Comparison of antenna measurement results in disturbed environment using a VHF spherical near field system
}

Gwenn Le Fur, Francisco Cano-Facila, Luc Duchesne, Daniel Belot, Lise Feat, Anthony Bellion, Romain Contreres, Kevin Elis

\section{To cite this version:}

Gwenn Le Fur, Francisco Cano-Facila, Luc Duchesne, Daniel Belot, Lise Feat, et al.. Comparison of antenna measurement results in disturbed environment using a VHF spherical near field system. International Conference on Antenna Measurements \& Applications; IEEE CAMA, Nov 2014, Antibes Juan les pins, France. 10.1109/CAMA.2014.7003330 . hal-01253522

\section{HAL Id: hal-01253522 \\ https://hal.science/hal-01253522}

Submitted on 11 Jan 2016

HAL is a multi-disciplinary open access archive for the deposit and dissemination of scientific research documents, whether they are published or not. The documents may come from teaching and research institutions in France or abroad, or from public or private research centers.
L'archive ouverte pluridisciplinaire HAL, est destinée au dépôt et à la diffusion de documents scientifiques de niveau recherche, publiés ou non, émanant des établissements d'enseignement et de recherche français ou étrangers, des laboratoires publics ou privés. 


\section{Comparison of Antenna Measurement Results in Disturbed Environment using a VHF Spherical Near Field System}

\author{
Gwenn Le Fur, Francisco Cano-Facila, \\ Luc Duchesne \\ R\&D Department \\ MVG - SATIMO Industries \\ Villebon-sur-Yvette, France \\ Gwenn.le-fur@satimo.fr
}

\begin{abstract}
This paper presents parts of investigations done in a VHF spherical Near-Field system in order to propose appropriate measurement procedure. First is briefly presented the mono-probe near field system and measurement challenges due to low frequencies. Then is presented the Antenna Under Test (AUT), the antenna pattern comparison approach and the measurement configurations. Finally, several measurement results using two scans configurations are compared to reference simulation result in order to find the most appropriate way of measurement suited to the measurement facility for the large wavelength considered.
\end{abstract}

\section{INTRODUCTION}

Recent needs for monitoring and tracking in low VHF range below $100 \mathrm{MHz}$ imply the use of specific antenna measurement facilities to characterize either the antenna alone or the antenna mounted on a supporting structure which can be heavy and bulky. Conventional outdoor far-field antenna measurement ranges used at UHF frequency bands and above become poorly effective down in VHF frequency band due to ground effects and electromagnetic pollution. Other implementations such as indoor far-field or compact range are not suitable at these very large wavelengths. The indoor NearField approach shows benefits in terms of compactness. However this approach involves issues due to high levels of reflectivity of the anechoic chamber and system components at these frequencies. Studies and characterizations of each component effect have been performed [1] and post processing techniques have been used and compared previously [2] to assess the system performances.

The proposed paper focuses on measurement configurations to properly characterize a very narrowband antenna taken as a reference. Considering the very narrow operational bandwidth the time filtering cannot be applied without removing critical antenna information. Thus this paper aims to propose an appropriate way to perform measurements dealing with the present reflections. By comparing the measurement results coming from two scan configurations to the simulation ones, is found a proper way to measure the

\author{
Daniel Belot, Lise Feat, Anthony Bellion, Romain \\ Contreres, Kevin Elis \\ $\mathrm{DCT} / \mathrm{RF} / \mathrm{AN}$ \\ CNES (French National Space Center) \\ Toulouse, France \\ Daniel.belot@cnes.fr
}

considered reference antenna in the considered CNES NearField system. Statistical approach is used to compare pattern results difference and a way to qualify the pattern results symmetry is proposed.

\section{CNES VHF NEAR-FIELD FACILITY}

The measurement used is the single probe spherical near field measurement system located in the chamber of the CNES in Toulouse France. This facility is dedicated to perform antenna measurement from $80 \mathrm{MHz}$ to $200 \mathrm{GHz}$ [3]. The chamber is shared by a compact range measurement system and a single probe near-field system. Above $400 \mathrm{MHz}$ the compact range configuration is used. Below $400 \mathrm{MHz}$ the nearfield configuration is used. Nevertheless classical foam pyramidal absorbers are poorly efficient below $200 \mathrm{MHz}$. Therefore ripples due to reflections coming from the compact range reflector and from the chamber walls are present. In order to extend the operational measurement bandwidth down $100 \mathrm{MHz}$ a new wide band and dual polarized VHF probe has been designed and manufactured [2] ( $c f$. Figure 1). All the measurement results presented in this paper have been done by using this new probe.

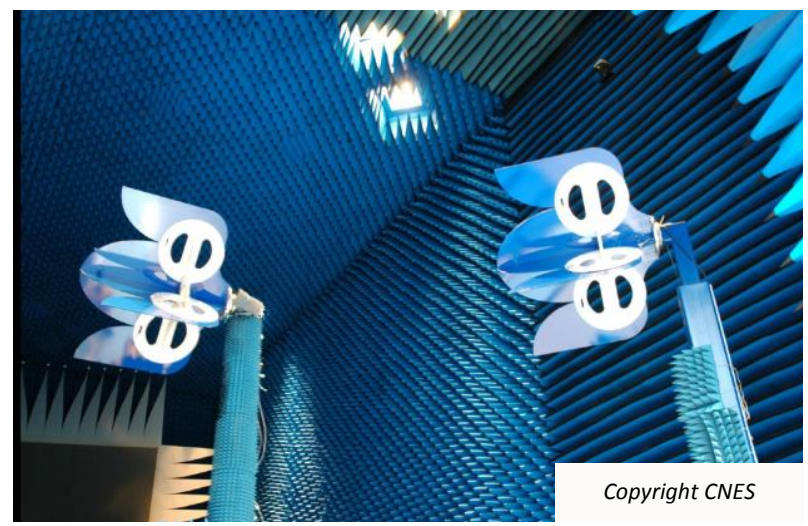

Figure 1 Photograph of the dual polarized probe in the CNES VHF Near-Field system 


\section{DETAILS OF INVESTIGATIONS}

\section{A. Antenna Under Test}

The Antenna Under Test (AUT) used for these investigations is a crossed double dipole mounted on a ground plane and working around $140 \mathrm{MHz}$ in a narrow bandwidth. The AUT is considered as a reference antenna i.e with a wellknown far-field pattern and a confident simulation model. The both dipoles are fed with equal amplitude signals with 90 degree phase difference. The expected symmetric far-field pattern covers a half sphere: $\varphi \in\left[0 ; 360^{\circ}\right]$ and $\theta \in\left[0 ; 90^{\circ}\right]$.

\section{B. Antenna Pattern Comparison Approach}

The strategy to compare measured patterns in the far-field region follows is the one used in [4] within the EU Antenna Centre of Excellence. Two far-field antenna patterns are compared using the weighted logarithmic difference to deemphasize the noise and the large spikes. The weighted function $W_{l o g}$ is composed by the $W_{n, 3}$ noise function and the pattern weighting function $W_{p}(\beta=0.3)$ [4]. Thus the weighted logarithmic difference between two patterns $f_{1}(\theta, \varphi)$ and $f_{2}(\theta, \varphi)$ can be expressed by:

$$
\Delta_{w, \log }(\theta, \varphi)=W_{\log } \Delta_{\log }(\theta, \varphi)
$$

With

$$
\Delta_{\log }(\theta, \varphi)=20 \log _{10} f_{1}(\theta, \varphi)-20 \log _{10} f_{2}(\theta, \varphi)
$$

Each measurement result are compared to the simulated pattern (obtained by using FEKO EM simulation software) taken as reference. Two classical figures of merits are used to quantify the difference between both antenna patterns namely the mean value and the standard deviation (STD). Results are reported in section IV.B.

\section{Measurement Configurations}

Considering the fixed near field probe ( $c f$. Figure 2) and its location inside the anechoic chamber, the AUT is moving around two axes (phi and theta) to perform the full sphere scan. As shown in Figure 2 the near field system is not located on a chamber axis of symmetry. Consequently the AUT could see different perturbations along the full sphere scan. Thus we considered and compared two ways of scanning the full sphere [5]:

- $\quad$ The "180 Phi” scan : $\theta \in[-180 ; 180]^{\circ}$ and $\varphi \in[0 ; 180]^{\circ}$

$$
\text { - } \quad \text { The "360 Phi" scan : } \theta \in[0 ; 180]^{\circ} \text { and } \varphi \in[0 ; 360]^{\circ}
$$

The "180 Phi" and "360 Phi" areas "seen" by the AUT are illustrated in the Figure 2 and Figure 3 respectively. Due to the theta excursion the "360 Phi" scan is expected to show more symmetric results than the "180 Phi" scan. Indeed in this last case perturbations coming from the CATR reflector are strongly different to the ones coming from the opposite wall. The amount of the perturbation should not be necessary lower but their effects are expected to be more homogeneous on the whole measurement sphere by using the "360 Phi" scan.

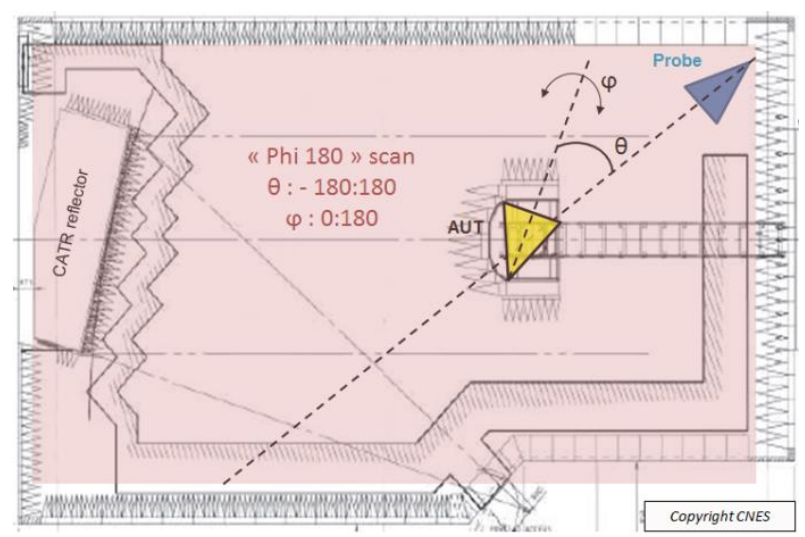

Figure 2 Illustration of the area seen by the AUT in the "180 phi" scan configuration - top view

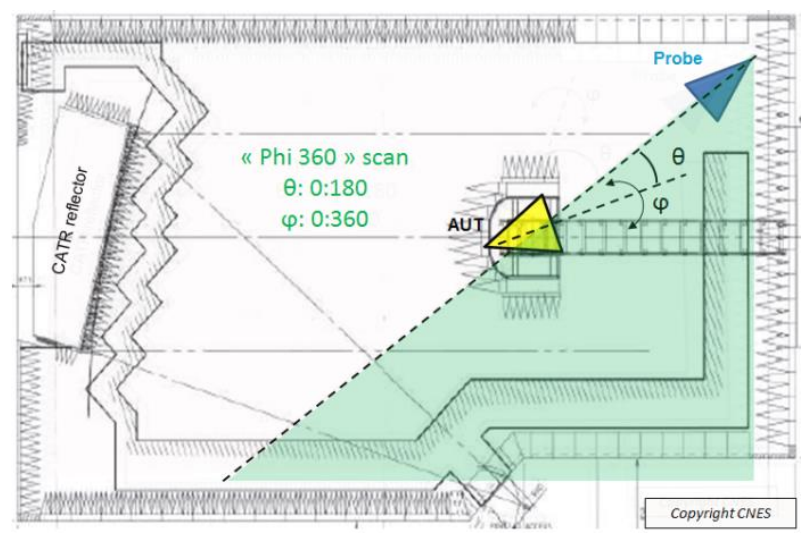

Figure 3 Illustration of the area seen by the AUT in the "360 phi" scan configuration - top view

\section{RESULTS COMPARISON}

A. 2D and cuts patterns qualitative results
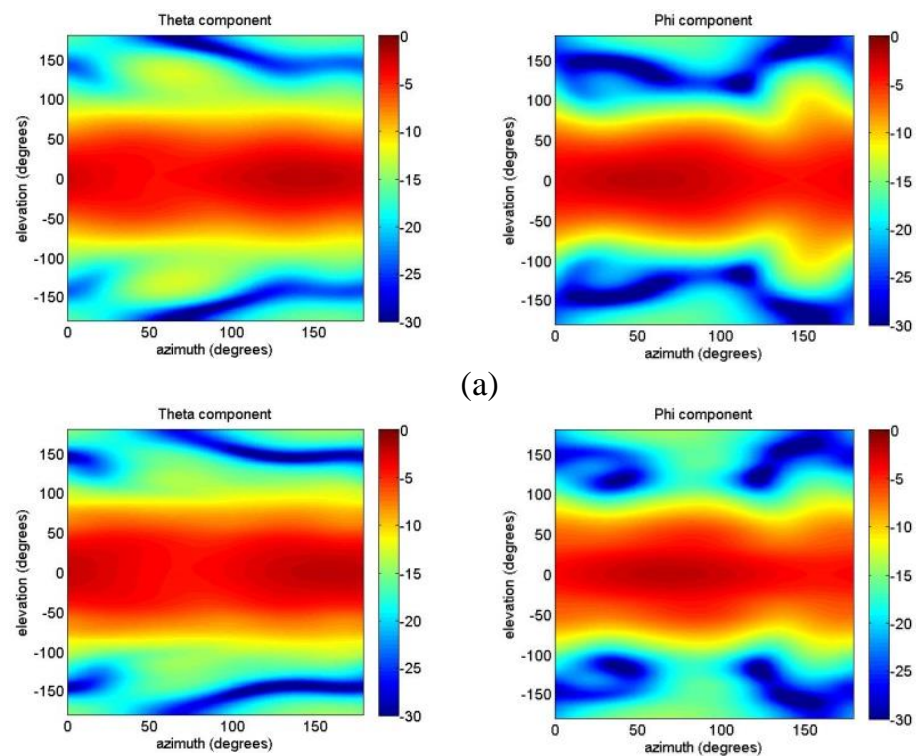

(a)

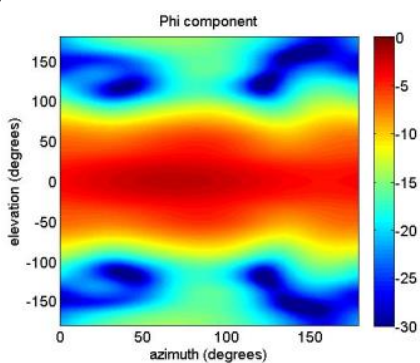

(b) 


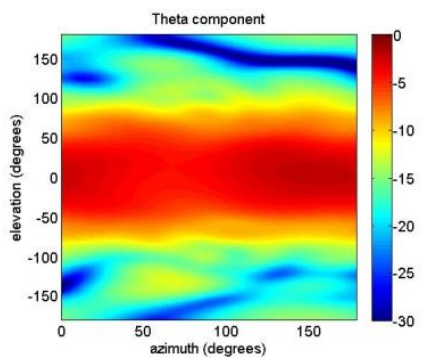

(c)

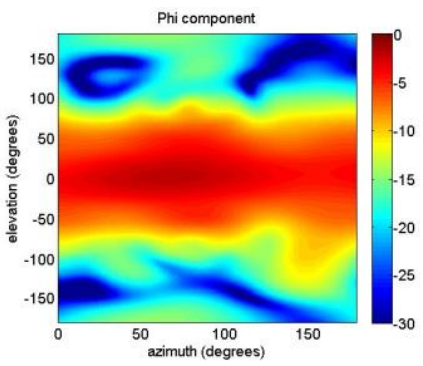

Figure 4 Examples of results around $140 \mathrm{MHz}$ - Elevation vs. azimuth plots - Theta (left) and Phi (right) normalized patterns

(a) Feko simulation - (b) CNES "360 Phi” measurement

(c) CNES "180 Phi” measurement

Figure 4 shows the 2D patterns results obtained through simulation and both measurement configurations. Both components of the field are plotted (in $\mathrm{dB}$ with $0 \mathrm{~dB}$ for max value). We observe at this stage a better agreement between the "360 Phi" scan and the simulation results. The "180 Phi" shows a globally good behavior but seems to be more impacted by perturbations. Moreover an asymmetry can be observed on the "180 Phi" results. These first observations are confirmed by plotting several pattern cuts shown in

Figure 5. At high patterns levels a good agreement is obtained between the three results. Differences can be observed for lower levels on some cuts.

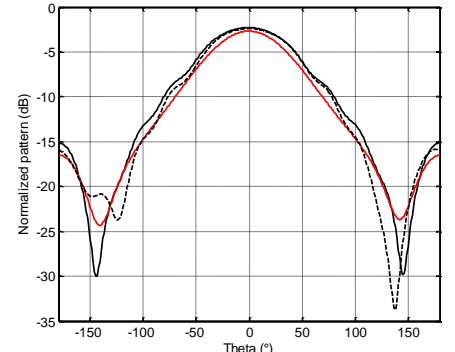

(a)

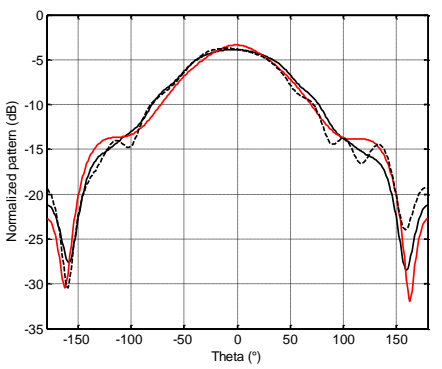

(c)

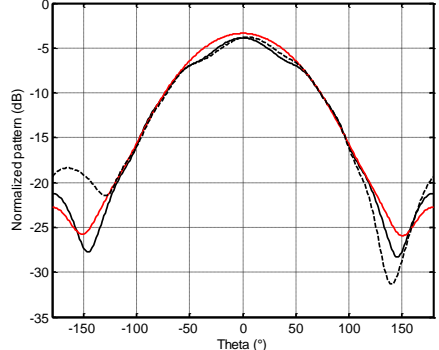

(b)

\begin{tabular}{|l|}
\hline -360 Phi \\
- Simulation \\
……. $180 \mathrm{Phi}$ \\
\hline
\end{tabular}

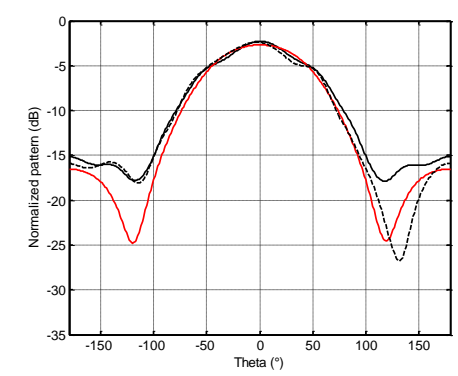

(d)
Figure 5 Comparison of radiation pattern cuts @ $140 \mathrm{MHz}$ Cut Phi $0^{\circ}$ - (a) Theta component - (b) Phi component Cut Phi $90^{\circ}$ - (c) Theta component - (d) Phi component

\section{B. Statistical data to quantify differences}

Pattern comparison approach briefly described before is applied on the two scan configurations. Differences are computed on the whole patterns cuts $\left(\theta \leq 180^{\circ}\right)$ between each scan configuration and simulation. Table 1 and

Table 2 synthetize the statistical values obtained for the "360 Phi" and "180 Phi" scan respectively. Both field components and four cuts are considered. Mean and STD values are computed and reported for each case.

TABLE 1 StATISTICAL FigURES OF MERITS FOR THE WEIGHTED DIFFERENCE BETWEEN “360 PHI” SCAN AND SIMULATION

\begin{tabular}{|l|c|c|c|c|}
\hline & \multicolumn{2}{|c|}{ ETheta component } & \multicolumn{2}{c|}{ EPhi component } \\
\hline Cuts & Mean $(\mathrm{dB})$ & STD $(\mathrm{dB})$ & Mean $(\mathrm{dB})$ & STD $(\mathrm{dB})$ \\
\hline Phi 0 & 0.38 & 0.82 & -0.30 & 0.48 \\
\hline Phi 45 & 0.01 & 0.78 & -0.01 & 1.47 \\
\hline Phi 90 & 0.03 & 0.70 & 0.93 & 0.88 \\
\hline Phi 135 & 0.31 & 1.27 & -1.10 & 1.63 \\
\hline
\end{tabular}

TABLE 2 STATISTICAL FIGURES OF MERITS FOR THE WEIGHTED DIFFERENCE BETWEEN “180 PHI” SCAN AND SIMULATION

\begin{tabular}{|l|c|c|c|c|}
\hline & \multicolumn{2}{|c|}{ ETheta component } & \multicolumn{2}{c|}{ EPhi component } \\
\hline Cuts & Mean $(\mathrm{dB})$ & STD $(\mathrm{dB})$ & Mean $(\mathrm{dB})$ & STD $(\mathrm{dB})$ \\
\hline Phi 0 & 0.03 & 1.07 & -0.10 & 1.14 \\
\hline Phi 45 & -0.01 & 0.59 & 0.68 & 1.18 \\
\hline Phi 90 & -0.01 & 0.88 & 0.36 & 1.07 \\
\hline Phi 135 & 0.21 & 1.41 & -0.02 & 1.67 \\
\hline
\end{tabular}

Looking on STD results the "180 Phi" scan shows differences slightly larger than the "360 Phi" scan. Mean values are even better for the " 180 Phi" scan. Thus the preliminary qualitative observations about pattern asymmetry are not confirmed by this statistical approach. This is due to the use of STD and means values on the whole patterns. Consequently is proposed hereafter a small observation approach of the pattern symmetry disparity.

\section{Pattern symmetry disparity}

In order to add an information about the expected pattern symmetry, we proposed here a simple way to appreciate it. On Figure 6 is plotted an example of weighted logarithmic difference for the both scan configurations. We can clearly see that this difference is more symmetrical along the pattern for the "360 Phi" scan. 


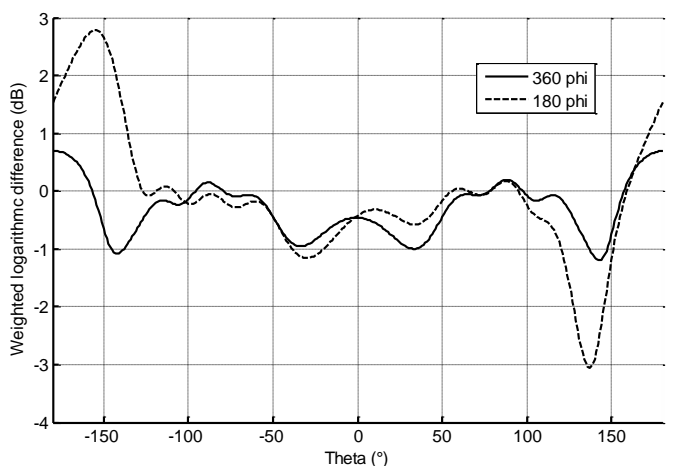

Figure 6 Weigthed logarithmic difference for the "360 Phi" and "180 Phi" scans - Cut Phi $0^{\circ}$ - Phi Component

To appreciate the symmetry disparity of the weighted difference, a second logarithmic difference is computed between the first one and itself "theta flipped". This simple approach is illustrated on Figure 7 for a cut of the "360 Phi" scan results where the red curve shows the symmetry disparity in $\mathrm{dB}$ on the whole cut i.e. the difference between the weighted difference on the considered cut and this same difference flipped in theta.

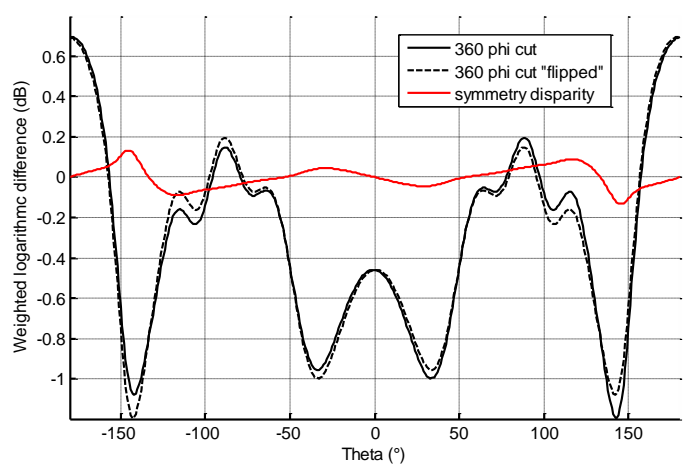

Figure 7 Weigthed logarithmic difference for the "360 Phi" and symmetry disparity - Cut Phi $0^{\circ}$ - Phi Component

On Figure 8 are reported the symmetry disparity for the two scan configurations. Four Phi cuts $\left(0^{\circ} / 45^{\circ} / 90^{\circ} / 135^{\circ}\right)$ for the Phi component are considered. An important gap between the two scan configurations is observed for all the considered cuts. The "360 Phi" scan results appear much more symmetric than the ones obtained by the "180 Phi" scan. This qualitative observation in addition with the statistical values obtained shows the benefit to perform the full sphere scan using the "360 Phi" scan configuration in the Near-Field CNES system.

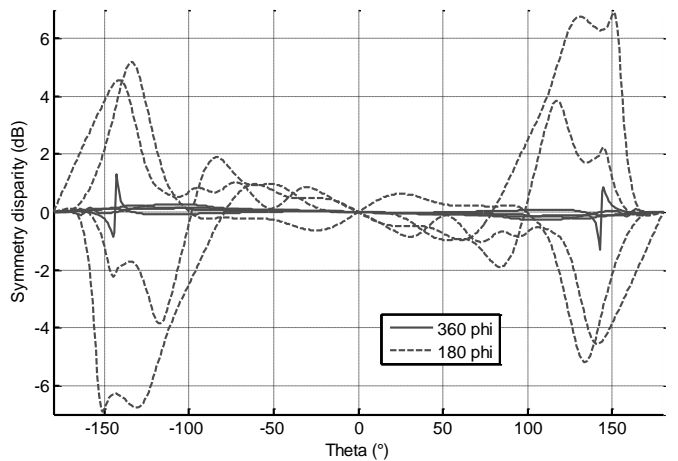

Figure 8 Symmetry disparity the " 360 Phi" and " 180 Phi" scans - Cut Phi $0^{\circ} / 45^{\circ} / 90^{\circ} / 135^{\circ}$ - Phi Component

\section{CONCLUSION AND PROSPECTS}

This paper proposes an appropriate way to perform measurements of a narrowband antenna dealing with the reflections present in the Near-Field system used. By comparing the measurement results coming from two scan configurations to the simulation ones, a proper way to measure the considered reference antenna in the CNES Near-Field system is found. Statistical approach is used to compare pattern results difference and an additional way to qualify the pattern results symmetry is proposed to choose the best measurement configuration. Additional global error budget of the system could be provided in the presentation.

\section{REFERENCES}

[1] Le Fur, G.; Duchesne, L.; Durand, L.; Bellion, A.; Belot, D., "Feasibility of indoor spherical near field antenna measurement facility in VHF range", Antenna Technology and Applied Electromagnetics (ANTEM), 2012 15th International Symposium on, pp.1,7, 25-28 June 2012.

[2] Le Fur, G.; Cano-Facila F.; Saccardi F.; Belot, D.; Durand L.; Duchesne L.; Foged L.; Lopez J-M.; Bellion, A. "Improvement of Antenna Measurement Results at Low Frequencies by Using Post-processing Techniques", EuCAP 2014 8th International Symposium on ,The Hague, The Nederlands.

[3] GDR Ondes "Rapport sur le recensement des chambres anéchoïques française et leurs perspectives » 2010

[4] Pivnenko, S.; Pallesen, J.E.; Breinbjerg, O.; Castaner, M.S.; Almena, P.C.; Portas, C.M.; Sanmartin, J.L.B.; Romeu, J.; Blanch, S.; GonzalezArbesu, J.M.; Sabatier, C.; Calderone, A; Portier, G.; Eriksson, H.; Zackrisson, J., "Comparison of Antenna Measurement Facilities With the DTU-ESA $12 \mathrm{GHz}$ Validation Standard Antenna Within the EU Antenna Centre of Excellence," Antennas and Propagation, IEEE Transactions on , vol.57, no.7, pp.1863-1878, July 2009

[5] G.E. Hindman and A.C. Newell, "Spherical near-field self-comparison measurements," in 26th AMTA Annual Meeting \& Symposium, Atlanta, Ga, USA, October 2004 